\title{
EVALUATION OF LOW COST ENVIRONMENT FRIENDLY NATURAL EXTRACTS FOR THE PURIFICATION OF DRINKING WATER
}

\author{
Asadullah Nawaz*, Faizan Arshad, Farva Khurshid
}

\section{Department of structures and environmental engineering, University of Agriculture Faisalabad *Corresponding author email: bajwaasad143@gmail.com}

This is an open access article distributed under the Creative Commons Attribution License, which permits unrestricted use, distribution, and reproduction in any medium, provided the original work is properly cited

\section{ARTICLE DETAILS}

\section{Article History:}

Received 12 November 2017 Accepted 12 December 2017 Available online 1 January 2018

\section{ABSTRACT}

\begin{abstract}
About 44\% citizens of Pakistan do not have access to safe drinking water. Good quality filters used for the purification of water are out of range for people of remote areas. This study has been conducted to check the efficiencies of different environment friendly materials which are locally available like Rice husk, incomplete burnt rice husk, Wheat husk and Saw dust. Collected materials were passed through pretreatment process like washing, drying and setup developed. Rice husk is burnt under solar concentrators. Samples of drinking water collected from different points from University of Agriculture Faisalabad. The results show that incomplete burnt rice husk is most efficient among all others in controlling different parameters of drinking water like TDS, EC, $\mathrm{PH}$, DO etc. For future it is recommended use rice husk in clay for the formation of filter setup and burns it in kiln. Biological parameters will also be check of drinking water after passing through this setup.
\end{abstract}

\section{KEYWORDS}

Drinking Water purification, Low cost Filter, Natural Extracts, Rice husk, Saw dust

\section{INTRODUCTION}

Fresh water is one of the most important resources crucial for the survival of all the living beings. It is even more important for the human being as they depend upon it for food production, industrial and waste disposal, as well as cultural requirement [1]. Human and ecological use of ground water depends upon ambient water quality. Human alteration of the landscape has an extensive influence on watershed hydrology Guru Nathan, 2006 [2].

Inadequate water supply is still one of the major challenges in developing countries. The Joint Monitoring Program (JMP) for Water Supply and Sanitation, implemented by the World Health Organization (WHO) and UNICEF, reports that 783 million people in the world $(11 \%$ of the total population) have no access to safe water, $84 \%$ of whom live in rural areas [3]. About 187 million people use surface water for drinking purposes; $94 \%$ of them are rural inhabitants and they are concentrated in sub-Saharan Africa [3].

Pakistanis are situated in southern Asia, bordering with India in the east, Afghanistan in the west, and China in the north. In the east of Pakistan, there exist mountains of Himalaya and Karakorum. In the north, Hindu Kush ranges exist, and hill regions (up to $4700 \mathrm{~m}$ ) in the northwest and in the upland Baluchistan plateau exist. The climatic conditions are mostly arid to semiarid with varying levels of average rainfalls in different areas of Pakistan [4].

Pakistan has been blessed by nature with enough surface and groundwater resources. Industrialization, urbanization, and rapid population growth have placed huge stress on water resources [5]. Water has a vital role in our life processes including growth and development. It plays significant role in our every field of life [6]. Due to technological developments, drinking water may contain various impurities, which are of physical, biological, and chemical nature [7].

Water pollution is a physical process that occurs in various water resources such as lakes, ground water, and rivers due to anthropogenic activities [8]. The utilization of poor quality water causes waterborne diseases and their spread. In Pakistan, about $50 \%$ of diseases and $40 \%$ of deaths occur due to poor drinking water quality reported in community health studies [9].

Drinking water should be free from color, turbidity, odor, and microbes. It should be esthetically pleasant. Due to increasing population of Faisalabad, contaminated water is the most alarming problem. In 1999,
Faisalabad required about 64.7 million gallons of drinking water supply daily to fulfill needs. But unfortunately, 3 million gallons of this water came from domestic pumps that come out from subsoil water and tube well [10]. According to Pakistan National Conservation Strategy, less rain, drought, and no development of other water resources reduce water availability and increase water scarcity [11].

This study is conducted to work out different crop materials and saw dust for purpose of Basic Physical drinking water treatment and to develop a filter setup by using environment friendly treatment materials.

\section{MATERIALS AND METHODS}

\subsection{Materials}

Following are the materials used to develop low cost filter with the help of natural extracts Rice husk, Wheat Husk, Saw Dust, Incomplete burnt Rice Husk, Sand, Gravel, Nylon Cloth, Metallic net, Filter setup.

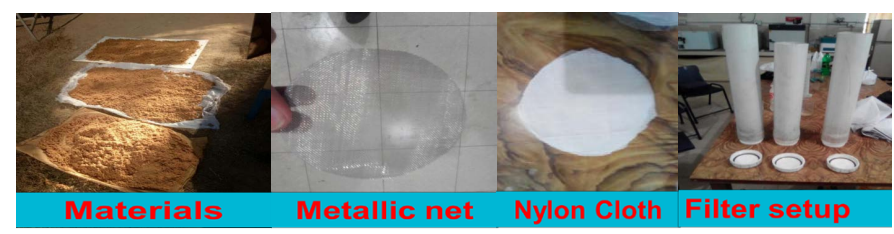

Figure 1: Materials and Filter setup

\subsection{Research Methodology}

\subsubsection{Formations of Filter}

Two formations were made to develop a low-cost filter with the help of natural extracts.

Table 1: Detail of the experimental formations

\begin{tabular}{|l|l|}
\hline \multicolumn{1}{|c|}{ Formation 1 } & \multicolumn{1}{c|}{ Formation 2 } \\
\hline Metallic net & Metallic net \\
\hline Nylon cloth=2foldsSand= 2in & Nylon cloth= 2folds \\
\hline Material= 8in & Sand= 3in \\
\hline Sand= 2in & Gravel= 2in \\
\hline Gravel= 2in & Material= 8in \\
\hline & Sand= 2in \\
\hline
\end{tabular}




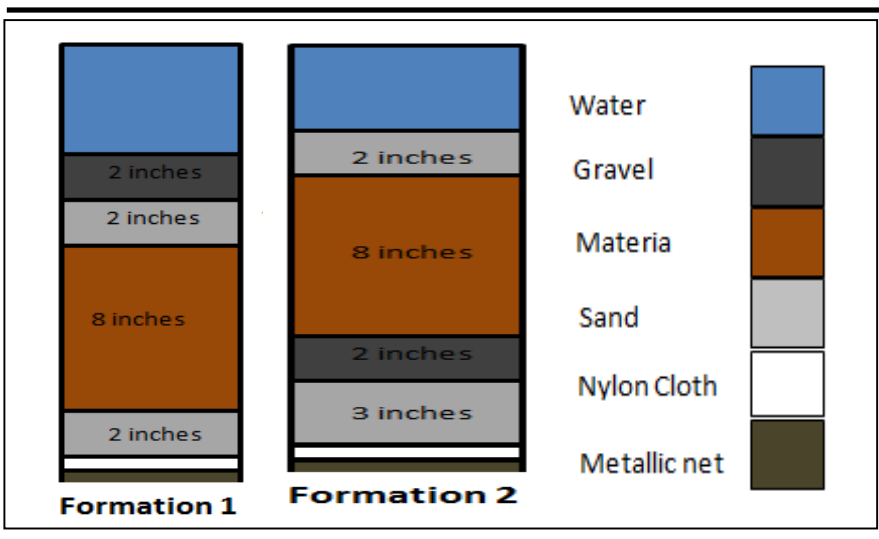

Figure 2: Order of formations

\subsubsection{Pretreatment processes}

The materials were collected from different shops in Faisalabad. Materials washed with abundance of clean water. Dust and other impurities were removed and placed in open environment for drying process. Rice husk is placed under solar concentrator for burning process. After burning process, rice husk washed for removal of over burnt rice husk.

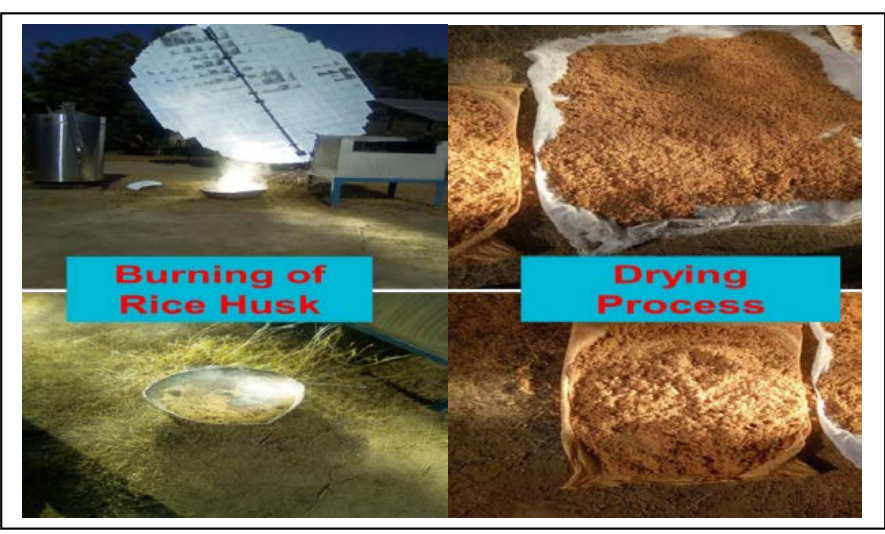

Figure 3: Pretreatment process

\subsection{Experimental Methodology}

The water samples were collected from different sources. Water samples were collected and stored in the Environmental Engineering laboratory to conduct detailed analysis of Physico-chemical Parameters which include Temperature, $\mathrm{pH}$, Electrical conductivity and TDS. Temperature, $\mathrm{pH}$ was recorded by using Thermometer and Digital $\mathrm{pH}$ Meter. Electrical conductivity was measured by using digital conductivity meter. The TDS values were measured by using TDS meter as shown in Figure 4 .

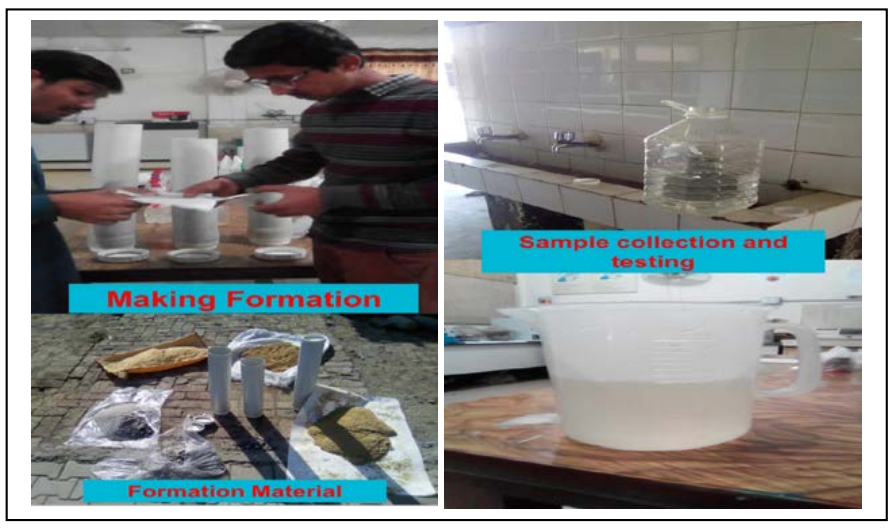

Figure 4: Experimental Procedure

\section{RESULTS AND DISCUSSION}

As basic purpose was to evaluate the efficiencies of natural extracts therefore the water samples collected and passed through the formation. After processing through the filters, parameters of samples rechecked and followed by following incomplete burnt rice husk decrease the TDS and EC to an acceptable level. Rice husk and saw dust showed relatively low efficiency as compared with incomplete burnt rice husk. Looking on the other hand water got more contamination after passing through the wheat husk. So, wheat husk is not useful for purification of drinking water.

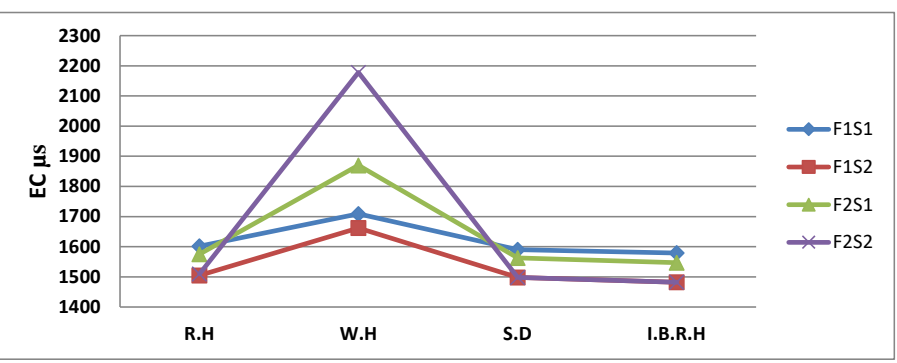

Figure 5: Electrical Conductivity Analysis of the samples for different formations

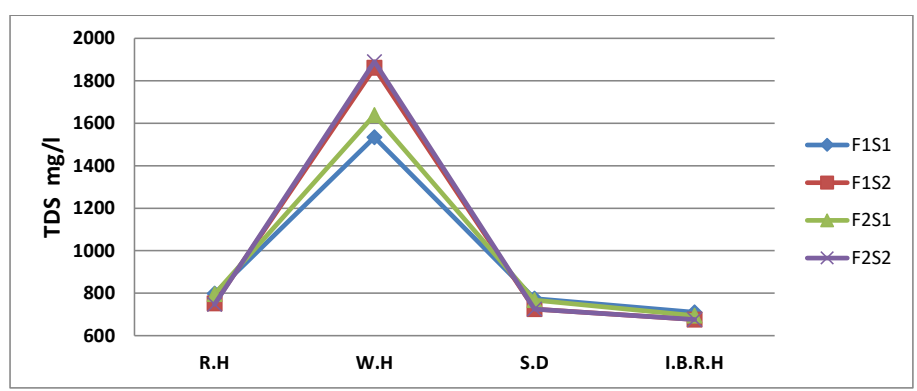

Figure 6: Total Dissolved Solids Analysis of the samples for different formations

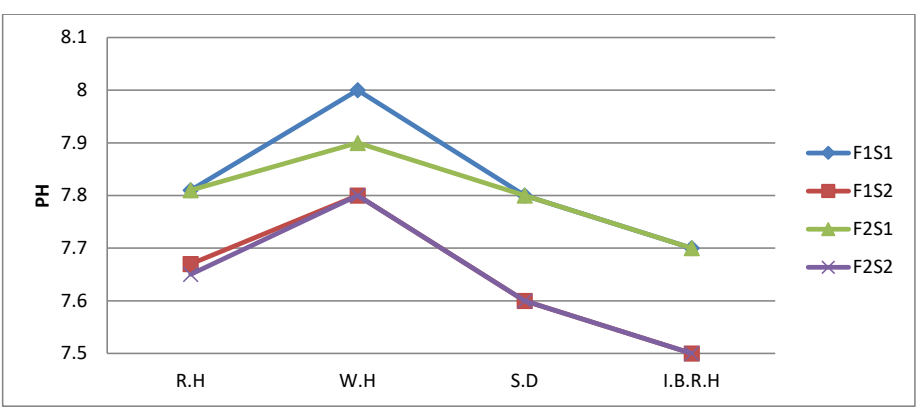

Figure 7: PH Values of the samples for different formations

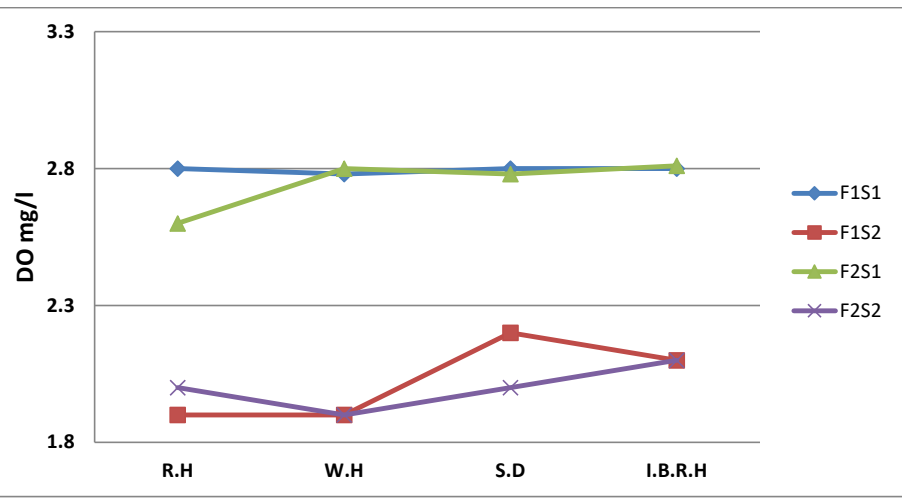

Figure 8: Dissolved Oxygen level of the samples for different formations

\section{CONCLUSION}

This research-based study is conducted in University of Agriculture Faisalabad to check the efficiencies of natural extracts and to develop a lowcost filter. Evaluation shows the trend of high efficiency to low efficiency Incomplete Burnt Rice Husk, Saw Dust and Rice Husk respectively. Wheat husk shows high impurity of color and also increase the values of physical parameters of drinking water like PH. Except Wheat Husk (strongly condemned) all materials especially Incomplete Burnt Rice Husk recommended for physical treatment of water.

\section{REFERENCES}

[1] Akpoveta, O.V., Okoh, B.E., Osakwe, S.A. 2011. Quality assessment of borehole water used in the vicinities of Benin, Edo State and Agbor, Delta State of Nigeria. Current Research in Chemistry, 3, 62-69.

[2] APHA, AWWA, WPCF. 2003. Standard Methods for Examination of Water and Wastewater. 20th Edition, American Public Health Association, Washington, DC. 
[3] WHO, UNICEF. 2012. Progress on Sanitation and Drinking Water: 2012 Update; World Health Organization/UNICEF: Geneva, Switzerland.

[4] WaterAid. 2012. Water quality testing protocol. Water Aid in Pakistan, $1-9$.

[5] Soomro, Z.A., Khokhar, M.IA., Hussain, W., Hussain, M. 2011. Drinking water Quality challenges in Pakistan. World Water Day, 17-28.

[6] Postel, S.L., Daily, G.C., Ehrlich, P.R. 1996. Human appropriation of renewable fresh water. Science, 271 (5250), 785-788.

[7] Park, K. 2007. Preventive and Social Medicine, M/S Banarsidus Bhanot, Prem Nagar, Jabalpur, India, 25th edition.
[8] Agarwal, S.K. 2002. Pollution Management, Water Pollution, A.P.H. Publishing Corporation, New Delhi, India.

[9] Chhatwal, R. 1990. Dictionary of Environmental Chemistry, Publication. New Delhi, India.

[10] Bashir, R., Nawaz, H., Khurshid, M. 1999. Chemical analysis of underground water of Faisalabad city. Pakistan Journal of Biological Sciences, 2 (3), 715-719.

[11] Hanson, A.J. 1992. Chapter 2 in Pakistan National Conservation Strategy, 36. 